\title{
Interspinous Posterior Devices IPD: A Miracle Cure for the Lumbar Spinal Stenosis?
}

\section{Alessandro Landi* and Roberto Delfini}

Department of Neurology and Psychiatry, Division of Neurosurgery, University of Rome Sapienza, Rome, Italy

\begin{abstract}
Interspinous Posterior Device (IPD) is a term used to identify a relatively recent group of implants used to treat lumbar spine stenosis with the presumed aim of a dynamic motion control systems. In the last 10 years there was a very large use of these implants. Despite this, no long-term clinical follow-up are available. In the literature is evident the high rate of reoperation, recurrence of symptoms and progression of degenerative changes. But his main question is: if these devices are effectively a miracle cure for the common problem of the lumbar spinal stenosis, why actually the use of IPD remains extremely controversial and should be investigated further?
\end{abstract}

Keywords: IPD; IFD; Biomechanics; Lumbar stenosis; Interspinous devices; Lumbar instability

Interspinous Posterior Device (IPD) is a term used to identify a relatively recent group of implants used to treat lumbar spine stenosis with the presumed aim of a dynamic motion control systems [1-4]. All of IPD are small devices implanted between the vertebral spinous processes [5-11]. After implantation, the device must be opened or expanded to distract (open) the neural foramen and decompress the roots [5-7]. These implants aim to restrict painful motion while otherwise enabling normal motion $[12,13]$. These devices (also called interspinous spacers) distract the laminar space and/or spinous processes and restrict extension. This procedure theoretically, enlarges the neural foramen and decompresses the roots, and could decompress the cauda equina in patients with spinal stenosis and neurogenic claudication [11-15].

The IPD have evolved over the years, being classified into bound or not bound depending on the presence or absence of a dynamic movement control only of the extension or both flexion-extensions [16]. A further evolution has also led to the development of IFD or Interspinous Fusion Devices. These implants have as their goal the interspinous bone fusion and, in my opinion, they cannot be classified as dynamic motion control systems because their target is metameric fusion [17-22]. In the last 10 years there was a very large use of these implants. Despite this, no long-term clinical follow-up are available. In the literature is evident the high rate of reoperation, recurrence of symptoms and progression of degenerative changes [7-26]. But his main question is: if these devices are effectively a miracle cure for the common problem of the lumbar spinal stenosis, why actually the use of IPD remains extremely controversial and should be investigated further? If we exclude the problems of the system's high cost, in my opinion, the main problem remains the pathologic substrate on which the devices have to act.

\section{Biomechanical Consideration}

If it is true that such devices can be used in patients with mild to moderate stenosis [5-8], either central or foraminal, or in low-grade spondylolisthesis without lysis (with poor or at least questionable results), it is also true that such devices can be used in cases in which the lumbar degenerative cascade is in active phase. The lumbar degenerative cascade, when is in active phase, has as its first step the disc degeneration, more or less advanced in relation to the extention and the continuity in time of the injury itself. Normally, as defined by Kirkaldy-Willis [27], the biomechanics of the lumbar spine follows a law that is called "rule of spine loading", in which the axial load of the body is distribute for the $80 \%$ on the intervertebral disc and $20 \%$ on the posterior structures (joints, ligaments and muscles) [1-4,21-25]. Disc degeneration transfers the axial load posteriorly, reversing the load distribution. This leads to the overload of the facet joints resulting in joint laxity, reduced competence of the joint capsules and hypermobility. The hypermobility stimulates the inflammatory reaction of adjacent tissues, this activates the Fractalkine in the yellow ligament [27] causing the increasing of the inflammatory cells recruitment which degrade the extracellular matrix of the ligament making it lose elasticity and causing hypertrophy. It is well documented the role of fraktalkine in the development of numerous inflammatory diseases (rheumatoid arthritis, dermatitis, etc.) and in ligaments and joints involved in inflammatory processes caused by instability (eg, joint capsules, ligaments, and synovium). The inflammatory process involves these tissues so the fractalkine over expression is activated; thus causing the recruitment of mononuclear cells within the LF feeding the inflammation and causing vascular injury and angiogenesis [27]. Moreover such an increase in mononuclear activity cause a proliferation of fibroblasts, (for over expression of TGF beta mRNA resulting in increased collagen fibers) and inflammatory cells in LF. This inflammatory cells activity in the LF causes rupture of the extracellular matrix (for activation of metalloproteinase MMP2) due to the elastin degradation, resulting in loss of elasticity of the ligament and subsequent hypertrophy [27]. In addition, the disk protrusion and prolapse and the yellow ligament hypertrophy cause reduction of the spinal canal diameter causing stenosis. In this phase, in which the articular hypertrophy generates foramina stenosis, and the collapse of the disc generates ligamentous hypertrophy, the stenosis becomes symptomatic, but the main substrate remains hypermobility anyway.

The non bound IPD is implanted between the vertebral spinous processes [28]. After implantation, the device is opened to distract the neural foramen and decompress the nerves. This procedure brings to the transfer of the axial load anteriorly on an already degenerated disc. In addition, the distraction that has to be made to open the foramina

*Corresponding author: Alessandro Landi, Department of Neurology and Psychiatry, Div. Neurosurgery, University of Rome Sapienza, Viale del Policlinico 155, 00100 Rome, Italy, Tel: +390649979105; E-mail: dott.alessandro.landi@gmail.com

Received October 26, 2013; Accepted January 20, 2014; Published February 02, 2014

Citation: Landi A, Delfini R (2014) Interspinous Posterior Devices IPD: A Miracle Cure for the Lumbar Spinal Stenosis? Surgery Curr Res 4: 162. doi:10.4172/21611076.1000162

Copyright: ( 2014 Landi A, et al. This is an open-access article distributed under the terms of the Creative Commons Attribution License, which permits unrestricted use, distribution, and reproduction in any medium, provided the original author and source are credited. 
alters the sagittal balance of the lumbar spine. The sagittal balance refers to the axial load in relation to the external environment, and its integrity gives the elastic properties to the spine.

The sagittal balance may be defined by the proper balancing of the physiological curvature, which is able to transfer the axial load through the pelvis and the femoral heads to the ground. This is possible by a perpendicular vector obtained from the external acoustic meatus, passing by the middle of the L5 endplate, the femoral heads and that reaches the floor. This line has to be posteriorly to the line between the femoral heads and it is essential that the curvatures of the spine are kept as physiological as possible. In particular, it is essential, at the lumbar level, the preservation of lordosis [1-4]. The goal of such devices is the insertion between the spinous processes and their distraction, as well as the transfer of the axial load anteriorly on a degenerated disc. These processes cause the alteration of the spinal biomechanics, impacting negatively on the sagittal balance. These actions cause changes in posture, spinal- pelvic axis rotations and alteration of the dorsal and cervical curvatures, which have as their purpose to compensate the alteration of the sagittal balance, but which have the effect of increasing the progression of spinal degeneration. Such patients are in a condition of spinal imbalance [7-9,12,14,16,18,29-34].

If such devices give an immediate improvement of the symptoms thanking to the foramen opening, long-term alteration of the biomechanics causes an acceleration of the degenerative process, either of the treated level or of the adjacent ones. Moreover, the overload of the spinous processes can result in their fractures or in lacerations of the posterior longitudinal ligament, causing the mobilization of the device $[7-14,35,36]$.

The bound IPD that have the presumed function of neutralizing the excessive movement in flexion-extension of the spine, when inserted have the goal of distraction of the spinous processes to open the foramina, which alters the lumbar biomechanics. Then even if these are able to control the excessive degrees of movement in flexion and extension, they have as consequence the non-physiological movement of spinal unit, with the same consequences as described before for the non bound IPD.

Specifically we can assure that the binding and unbinding properties are specific for the IPD; in particular the bound IPD have a particular concept in materials and design for which it must be adherent to the above and below spinal process (such as WALLIS implant or DIAM implant for example). This design complains laces, strings and much more. The unbound IPD instead have no adherence to the spinal processes (such as APERIUS, X-STOP, BACJAC ecc). This difference in design reflects a difference in biomechanical behaviour: in fact the unbound devices restrict (and no arrest) the motion only in flexion and the bound devices restrict the motion both in flexion than in extension.

Moreover the metameric instability is not limited to flexionextension movements, but also and above all of lateral bending and axial rotation. These movements are often associated with the flexionextension when complex movements are done. An interspinous device cannot control the rotation and the lateral bending in any way. Those movements are burdened by excessive load after the insertion of the device, which then enhances and accelerates the degenerative process [7-13,37,38].

\section{Conclusions}

The real problem is the biomechanic behaviour of the spine when these devices are implanted. So in my opinion the real indications for IPD implants are extremely restricted, and reserved only to the bound
IPD, because this type of devices is the only ones with a slight control of the hypermovement. But when there are clear signs of metameric instability, these devices should never be implanted.

\section{References}

1. Solomonow M, Zhou BH, Harris M, Lu Y, Baratta RV (1998) The ligamentomuscular stabilizing system of the spine. Spine (Phila Pa 1976) 23: 2552-2562.

2. Hindle RJ, Pearcy MJ, Cross A (1990) Mechanical function of the human lumbar interspinous and supraspinous ligaments. J Biomed Eng 12: 340-344.

3. Sharma M, Langrana NA, Rodriguez J (1995) Role of ligaments and facets in lumbar spinal stability. Spine (Phila Pa 1976) 20: 887-900.

4. Busscher I, van Dieën JH, Kingma I, van der Veen AJ, Verkerke GJ, et al. (2009) Biomechanical characteristics of different regions of the human spine: an in vitro study on multilevel spinal segments. Spine (Phila Pa 1976) 34: 2858 2864 .

5. Heuer F, Schmidt H Käfer W, Graf N Wilke HJ (2012) Posterior motion preserving implants evaluated by means of intervertebral disc bulging and annular fiber strains. Clin Biomech (Bristol, Avon) 27: 218-225.

6. Floman Y, Millgram MA, Smorgick Y, Rand N, Ashkenazi E (2007) Failure of the Wallis interspinous implant to lower the incidence of recurrent lumbar disc herniations in patients undergoing primary disc excision. J Spinal Disord Tech 20: 337-341.

7. Sun HL, Li CD, Liu XY, Lin JR, Yi XD, et al. (2011) [Mid-term follow-up and analysis of the failure cases of interspinous implants for degenerative lumbar diseases]. Beijing Da Xue Xue Bao 43: 690-695.

8. Verhoof OJ, Bron JL, Wapstra FH, van Royen BJ (2008) High failure rate of the interspinous distraction device (X-Stop) for the treatment of lumbar spinal stenosis caused by degenerative spondylolisthesis. Eur Spine J 17: 188-192.

9. Maida G, Marcati E, Sarubbo S (2012) Heterotopic ossification in vertebra interlaminar/interspinous instrumentation: report of a case. Case Rep Surg 2012: 970642

10. Bowers C, Amini A, Dailey AT, Schmidt MH (2010) Dynamic interspinous process stabilization: review of complications associated with the X-Stop device. Neurosurg Focus 28: E8.

11. Barbagallo GM, Olindo G, Corbino L, Albanese V (2009) Analysis of complications in patients treated with the X-Stop Interspinous Process Decompression System: proposal for a novel anatomic scoring system for patient selection and review of the literature. Neurosurgery 65: 111-119.

12. Epstein NE (2009) X-Stop: foot drop. Spine J 9: e6-e9.

13. Korovessis P, Repantis T, Zacharatos S, Zafiropoulos A (2009) Does Wallis implant reduce adjacent segment degeneration above lumbosacral instrumented fusion? Eur Spine J 18: 830-840.

14. Tamburrelli FC, Proietti L, Logroscino CA (2011) Critical analysis of lumbar interspinous devices failures: a retrospective study. Eur Spine J 20 Suppl 1 : S27-35

15. Trautwein FT, Lowery GL, Wharton ND, Hipp JA, Chomiak RJ (2010) Determination of the in vivo posterior loading environment of the Coflex interlaminar-interspinous implant. Spine J 10: 244-251.

16. Landi A (2013) Elastic resistance of the spine: Why does motion preservation surgery almost fail? World J Clin Cases 1: 134-139.

17. Techy F, Mageswaran P, Colbrunn RW, Bonner TF, McLain RF (2013) Properties of an interspinous fixation device (ISD) in lumbar fusion constructs: a biomechanical study. Spine J 13: 572-579.

18. Gonzalez-Blohm SA, Doulgeris JJ, Aghayev K, Lee WE 3rd, Volkov A, et al. (2013) Biomechanical analysis of an interspinous fusion device as a standalone and as supplemental fixation to posterior expandable interbody cages in the lumbar spine. J Neurosurg Spine.

19. Karahalios DG, Kaibara T, Porter RW, Kakarla UK, Reyes PM, et al. (2010) Biomechanics of a lumbar interspinous anchor with anterior lumbar interbody fusion. J Neurosurg Spine 12: 372-380.

20. Tian NF, Zhang XL, Wu YS, Jiang LB, Xu HZ, et al. (2012) Fusion after interspinous device placement. Orthopedics 35: e1822-1825.

21. Adams MA, Hutton WC, Stott JR. The resistance to flexion of the lumbarintervertebral joint. Spine (Phila Pa 1976). 1980 May-Jun 5(3): 245-253. 
Citation: Landi A, Delfini R (2014) Interspinous Posterior Devices IPD: A Miracle Cure for the Lumbar Spinal Stenosis? Surgery Curr Res 4: 162. doi:10.4172/2161-1076.1000162

22. Biomechanical analysis in a human cadaveric model of spinous process fixation with an interlaminar allograft spacer for lumbar spinal stenosis: Laboratory investigation. J Neurosurg Spine 16(6): 585-593.

23. Kaibara T, Karahalios DG, Porter RW, Kakarla UK, Reyes PM, et al. (2010) Biomechanics of a lumbar interspinous anchor with transforaminal lumbar interbody fixation. World Neurosurg 73: 572-577.

24. Adams MA, Hutton WC, Stott JR (1980) The resistance to flexion of the lumbar intervertebral joint. Spine (Phila Pa 1976) 5: 245-253.

25. Gudavalli MR, Triano JJ (1999) An analytical model of lumbar motion segment in flexion. J Manipulative Physiol Ther 22: 201-208.

26. Anderson AL, Mclff TE, Asher MA, Burton DC, Glattes RC (2009) The effect of posterior thoracic spine anatomical structures on motion segment flexion stiffness. Spine (Phila Pa 1976) 34: 441-446.

27. Yong-Hing K, Kirkaldy-Willis WH (1983) The pathophysiology of degenerative disease of the lumbar spine. Orthop Clin North Am 14: 491-504.

28. Landi A (2013) Delfini R. Soft stenosis of the lumbar spine: Thickness vs Hypertrophy of the ligamentum flavum. A patogenetic and molecular point of view. J Spine 2: e11.

29. Landi A (2013) Elastic resistance of the spine: Why does motion preservation surgery almost fail? World J Clin Cases 1: 134-139.

30. Ploumis A, Christodoulou P, Kapoutsis D, Gelalis I, Vraggalas V, et al. (2012) Surgical treatment of lumbar spinal stenosis with microdecompression and interspinous distraction device insertion. A case series. J Orthop Surg Res 7: 35.
31. Buric J, Pulidori M, Sinan T, Mehraj S (2011) DIAM device for low back pain in degenerative disc disease : 24 months follow-up. Acta Neurochir Suppl 108: 177-182.

32. Nardi P, Cabezas D, Rea G, Pettorini BL (2010) Aperius PercLID stand alone interspinous system for the treatment of degenerative lumbar stenosis: experience on 152 cases. J Spinal Disord Tech 23: 203-207.

33. Anderson PA, Tribus CB, Kitchel SH (2006) Treatment of neurogenic claudication by interspinous decompression: application of the X STOP device in patients with lumbar degenerative spondylolisthesis. J Neurosurg Spine 4 463-471.

34. Postacchini R, Ferrari E, Cinotti G, Menchetti PP, Postacchini F (2011) Aperius interspinous implant versus open surgical decompression in lumbar spinal stenosis. Spine J 11: 933-939.

35. Lauryssen C (2007) Appropriate selection of patients with lumbar spinal stenosis for interspinous process decompression with the X STOP device. Neurosurg Focus 22: E5

36. Gillespie KA, Dickey JP (2004) Biomechanical role of lumbar spine ligaments in flexion and extension: determination using a parallel linkage robot and a porcine model. Spine 29: 1208-1216.

37. Pradhan BB, Turner AW, Zatushevsky MA, Cornwall GB, Rajaee SS, et al. (2012) Biomechanical analysis in a human cadaveric model of spinous process fixation with an interlaminar allograft spacer for lumbar spinal stenosis: Laboratory investigation. J Neurosurg Spine 16: 585-593.

38. Kirkaldy-Willis WH, Yong-Hing K (1983) The pathophysiology of degenerative disease of the lumbar spine. Orthop Clin North Am 14: 491-504. 